\title{
Effect of Number and Position of Rotational Friction Dampers on Seismic Response of Steel Frame
}

\author{
Ionuț-Sergiu Oance and Sunai Gelmambet
}

\begin{abstract}
This paper deals with effect of number and position of friction dampers on seismic response of $2 \mathrm{D}$ steel frame. For the present study four structures with six storeys are subjected to a time history analysis. For each story are using two, four and six friction dampers with different positions keeping slip load and stiffness constant. To study the effect of number and position of dampers in structures, are analysed the time period, top roof displacement, maximum base shear and percentage energy dissipated in accordance with energy induced in the frame. The results indicate that number and placement of damper affects the structural response. A large number of dampers do not always lead to best benefit in terms of energy dissipation.
\end{abstract}

Keywords - dissipation energy, friction damper non-linear time, history analysis

\section{INTRODUCTION}

Earthquake-resistant design of structures using energy dissipation devices such as viscoelastic dampers, viscous fluid dampers, metallic dampers and friction dampers have proved the potential for reducing seismic risk without compromising the safety and reliability. Friction dampers have revealed to be capable of providing structures with considerable added damping to reduce the member forces, joint displacement, and floor acceleration of structures produced due to seismic excitations [1].

The present paper presents the effect of number and position of friction damper on the seismic response of 2D frame structure. Non-linear times-history analysis using Vrancea 1977 ground motion record scaled to $0.3 \mathrm{~g}$ was performed for each structure.

\section{EXPERIMENT DESCRIPTION}

For evaluating the behavior of structures for different number and position of friction dampers, a nonlinear dynamic time-history analysis was used. This tipe of analysis show the response of the structure during seismic action. The property of friction damper are shown in Table 1. The mechanism of rotational friction dampers is shown in Fig. 1.

The program ETABS 17 [2] was used to assess the response of structures. Four design scenarios were taken into consideration using different positioning and number of the $50 \mathrm{KN}$ slip load dampers. 
Table 1. Properties of friction damper

\begin{tabular}{|c|c|}
\hline Element used for modeling & Plastic (Wen) \\
\hline Slip load & $50 \mathrm{KN}$ \\
\hline Stiffness & $149833,33 \mathrm{KN} / \mathrm{m}$ \\
\hline Post yield stiffness ratio & 0,0001 \\
\hline Yielding exponent & 10 \\
\hline
\end{tabular}
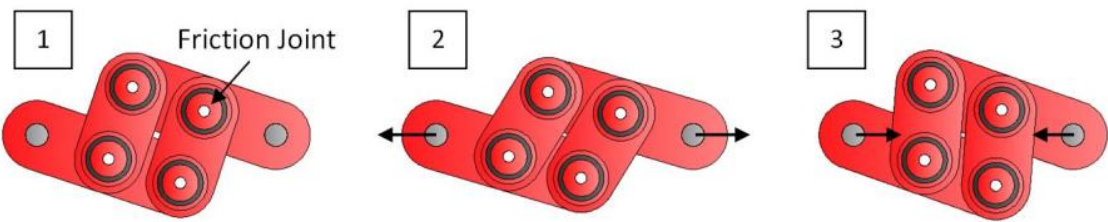

Fig. 1. Mechanism of friction damper in brace [3]

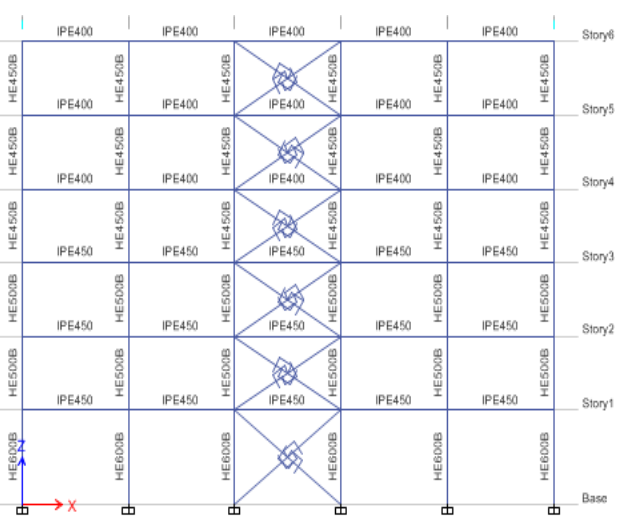

Fig. 2. Structure 1

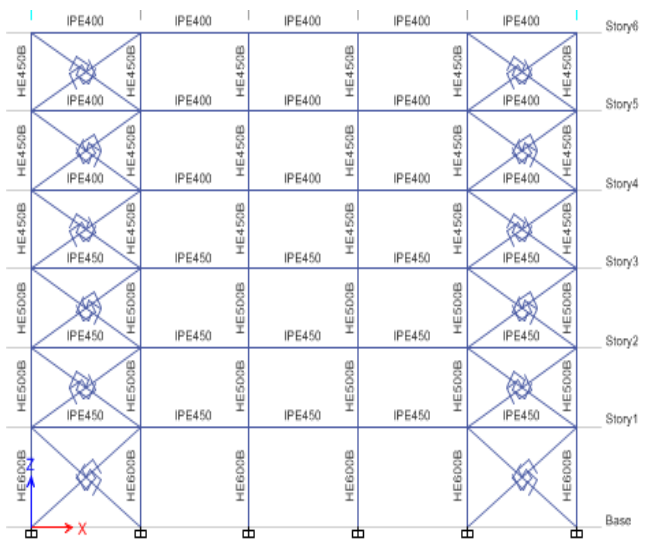

Fig. 4. Structure 3

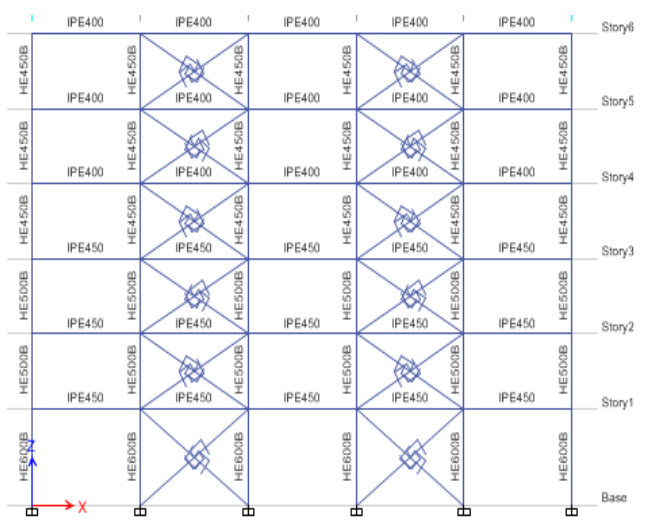

Fig. 3. Structure 2

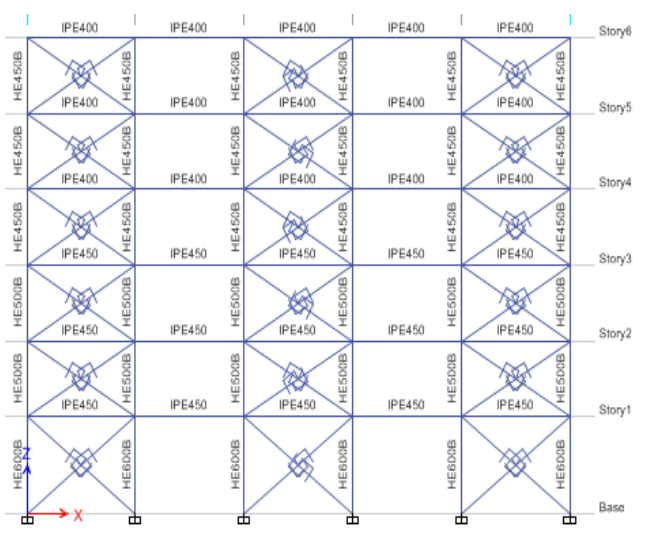

Fig. 5. Structure 4

The span length is $6 \mathrm{~m}$, first level has 4,5 m height, and rest of levels have 3,5 $\mathrm{m}$. The material is Steel S355. The response of structures in all four design versions was subjected 
to Vrancea 1977 earthquake recording (Fig. 6) scaled to 0,3g. The response in terms of top roof maximum displacement, maximum base shear and percentage energy dissipated in accordance with energy induced in the frame are listed below.

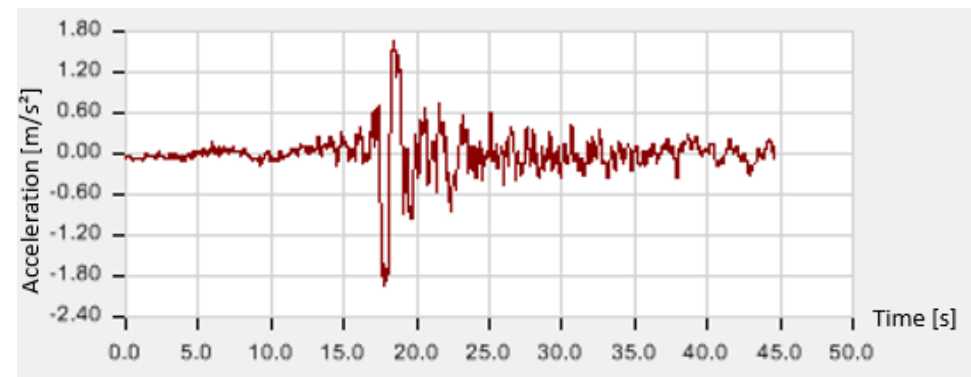

Fig. 6. Earthquake Vrancea 1977 accelerogram

\section{RESULTS AND SIGNIFICANCES}

In Table 2 are evaluated the dynamic characteristics of the structures in terms of periods of vibration. The fundamental period of the structure 1 is $18,3 \%$ bigger than the average of last three structures. The structures 2, 3, 4 have similar fundamental periods.

Table. 2. Dynamic Characteristics of Structures

\begin{tabular}{|c|c|c|c|c|}
\hline- & Structure 1 & Structure 2 & Structure 3 & Structure 4 \\
\hline \multirow{4}{*}{ Periods [s] } & 0,633 & 0,475 & 0,474 & 0,396 \\
\cline { 2 - 5 } & 0,214 & 0,161 & 0,163 & 0,136 \\
\cline { 2 - 5 } & 0,124 & 0,117 & 0,117 & 0,116 \\
\cline { 2 - 5 } & 0,117 & 0,115 & 0,113 & 0,105 \\
\cline { 2 - 5 } & 0,115 & 0,091 & 0,105 & 0,103 \\
\hline
\end{tabular}

From the Figure 7 it has been observed that the maximum top displacement for structure 1 is greater than the rest of the structures, while the structure number 4 has the lowest displacement. The maximum displacement values of structures 2 and 3 are both closed to $60 \mathrm{~mm}$.

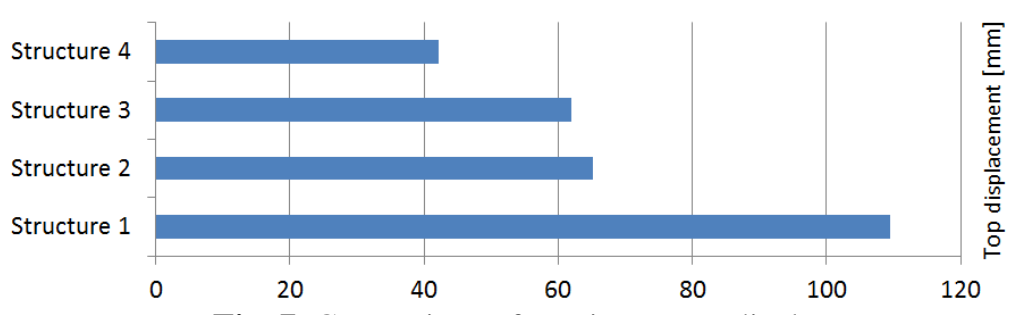

Fig. 7. Comparison of maximum top displacement

By observing the maximum story base shear for structure 1 , the value is more than the other three structures. The structures 2, 3 and 4 have appropriate values around $3400 \mathrm{KN}$ (Fig.8). 


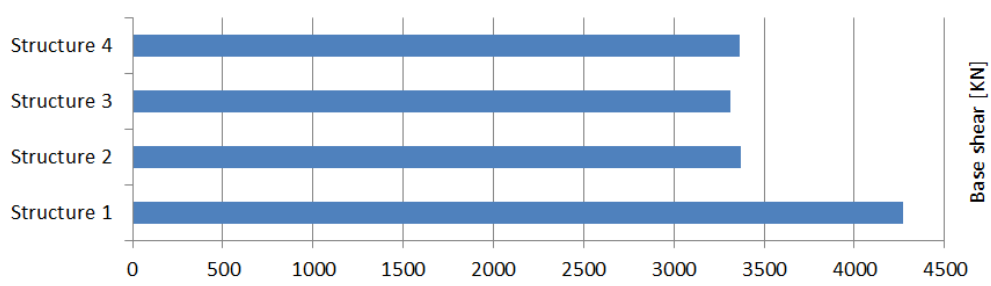

Fig. 8. Comparison of maximum base shear

From Figure 9 it is clear that structure 1 has the values of input energy greater than the others three structures. The structures 2, 3 and 4 have appropriate values.

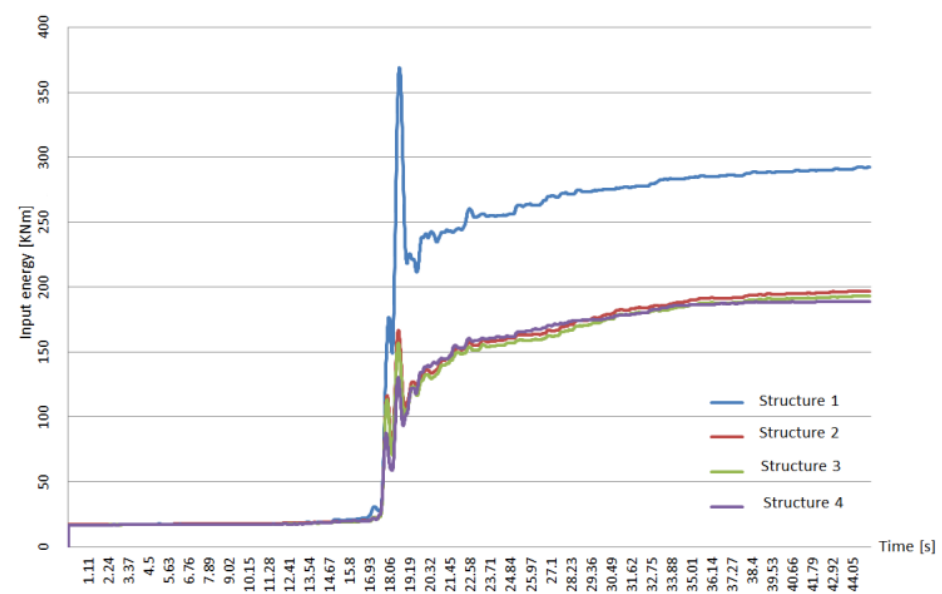

Fig. 9. Comparison of input energy

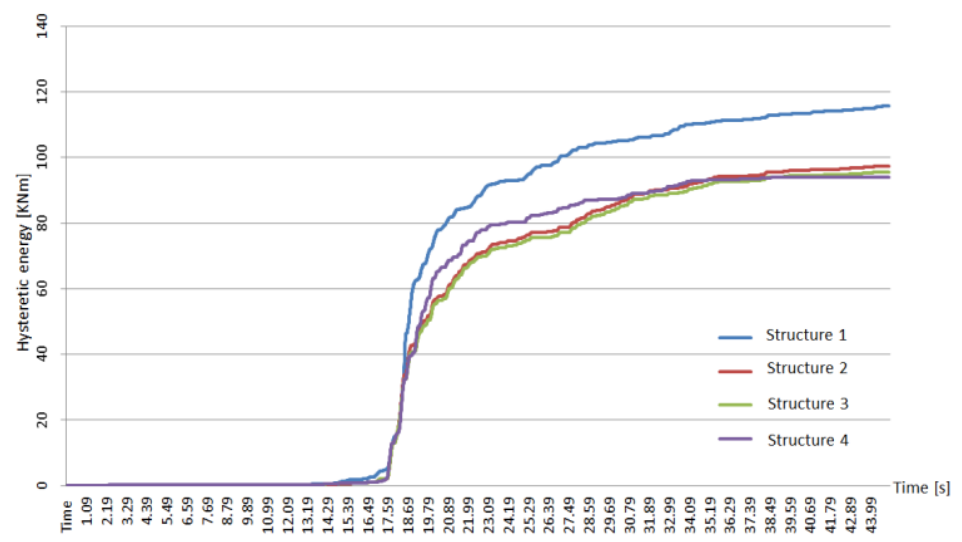

Fig. 10. Comparison of hysteretic energy

The maximum hysteretic energy is induced in structure 1. Structures 2 and 3 have similar values (Fig. 10). Table 3 shows that the values of input energy and dissipated energy through friction dampers are different for each structure. It is visible that by keeping number of friction dampers same but changing its location, changes input energy and dissipated energy in the structure. 
Table. 3. The maximum values of dissipation energy for each structure

\begin{tabular}{|c|c|c|c|}
\hline Structure & $\begin{array}{c}\text { Input energy } \\
{[\mathbf{K N m}]}\end{array}$ & $\begin{array}{c}\text { Hysteretic } \\
\text { energy [KNm] }\end{array}$ & $\begin{array}{c}\text { Dissipation } \\
{[\mathbf{\%}]}\end{array}$ \\
\hline Structure 1 & 292,55 & 115,79 & 39,58 \\
\hline Structure 2 & 196,79 & 97,28 & 49,43 \\
\hline Structure 3 & 192,93 & 95,55 & 49,53 \\
\hline Structure 4 & 188,82 & 93,94 & 49,75 \\
\hline
\end{tabular}

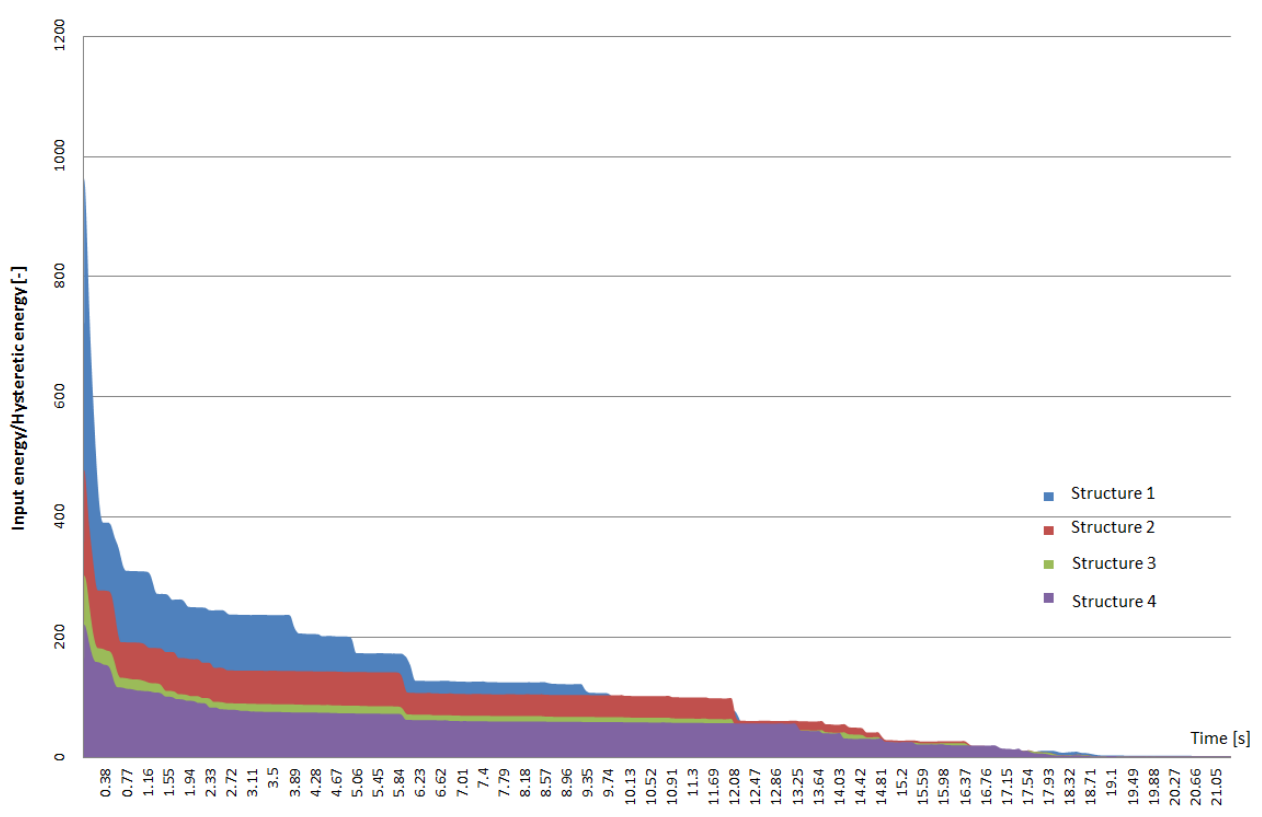

Fig. 11. The dissipation energy in time

Even the maximum percentage energy dissipation for structure 2,3,4 are around 49,5\%, the Figure 11 shows that dissipation energy in time for structure 3 is quite similar with structure 4 .

\section{CONCLUSION}

This study shows that that number and placement of damper affects the structural response in terms of energy.

It is visible that structure with six friction dampers per story has the minimum response in terms of top roof displacement, but the Structure 3 is optimal solution in terms of dissipated energy. A large number of dampers do not always lead to best benefit in terms of energy dissipation. 


\section{sciendo}

104 Ovidius University Annals Series: Civil Engineering, Year 21, 2019

\section{REFERENCES}

[1] S.S. Sanghai and P.Y. Pawade (2014), Effect of Position and Number of Friction Dampers on seismic response of Frame, International Journal of Earth Sciences and Engineering, ISSN 0974-5904, Volume 07, No. 05

[2] https://www.csiamerica.com/

[3] https://www.damptech.com/diagponal-bracing

\section{Note:}

Ionut-Sergiu Oance - Ovidius University of Constanta, Doctoral School of Applied Sciences, Constanta, Romania, (e-mail: ionut_oance@yahoo.com)

Gelmambet Sunai - Ovidius University of Constanta, Bd. Mamaia nr.124, 900356 - Constanta, Romania (e-mail: gelmambets@univ-ovidius.ro) 